\title{
Bernardin de Saint-Pierre, CEuvres complètes, t. 1, Romans et contes
}

\section{Simón Gallegos Gabilondo}

\section{(2) OpenEdition}

1 Journals

\section{Edizione digitale}

URL: http://journals.openedition.org/studifrancesi/4378

DOI: 10.4000/studifrancesi.4378

ISSN: 2421-5856

\section{Editore}

Rosenberg \& Sellier

\section{Edizione cartacea}

Data di pubblicazione: 1 settembre 2016

Paginazione: 332

ISSN: 0039-2944

\section{Notizia bibliografica digitale}

Simón Gallegos Gabilondo, "Bernardin de Saint-Pierre, E Euvres complètes, t. 1, Romans et contes », Studi Francesi [Online], 179 (LX | II) | 2016, online dal 01 septembre 2016, consultato il 17 septembre 2020. URL : http://journals.openedition.org/studifrancesi/4378 ; DOI : https://doi.org/10.4000/ studifrancesi.4378

Questo documento è stato generato automaticamente il 17 settembre 2020.

\section{(c)}

Studi Francesi è distribuita con Licenza Creative Commons Attribuzione - Non commerciale - Non opere derivate 4.0 Internazionale. 


\title{
Bernardin de Saint-Pierre, CEuvres complètes, t. 1, Romans et contes
}

\author{
Simón Gallegos Gabilondo
}

\section{NOTIZIA}

BERNARDIN DE SAINT-PIERRE, CEuvres complètes, t. 1, Romans et contes, Jean-Michel Racault (dir.), Paris, Classiques Garnier, 2014, 1051 pp.

In occasione del bicentenario della morte di Bernardin de Saint-Pierre, la pubblicazione del primo tomo delle sue opere complete presenta Paul et Virginie, L'Arcadie, La Chaumière indienne e l'inedita Histoire de l'Indien in un'edizione curata da Jean-Michel Racault, Guilhem Armand, Colas Duflo e Chantale Meure. La realizzazione di questo fortunato progetto editoriale viene a colmare una lacuna molto sentita - l'ultima edizione di tutte le opere dell'autore risale al 1818 - non soltanto dagli specialisti, che troveranno un apparato critico rigoroso, ma anche da un pubblico di lettori che ritroveranno testi talvolta poco reperibili. Il presente volume, al quale farà seguito un altro dedicato ai viaggi, oltre a contenere i romanzi e i racconti, è arricchito dai paratesti che caratterizzano la produzione dell'autore, quali le note, le appendici e i preamboli che fanno parte a pieno titolo dell'opera. L'itinerario irregolare della scrittura del celebre letterato, i cui libri pubblicati rimanevano aperti ad aggiunte successive, si svolge attraverso testi letterari, scientifici, filosofici e politici. Già nei Voyages à l'île de France (1773) aveva descritto senza abbellimenti le colonie francesi e la pratica della schiavitù, facendo appello a un'indignazione minoritaria tanto presso l'opinione pubblica quanto nei salotti parigini, ma che rifletteva un sentimento che si andava diffondendo attraverso la letteratura antischiavista. Il racconto epistolare del soggiorno nell'isola Maurizio ritrae la dominazione dei coloni sugli schiavi in uno stile che, a prima vista, lo avvicinerebbe alla cerchia dei critici di una schiavitù astratta. Tuttavia, le strade che avevano incitato Bernardin de Saint-Pierre alla difesa di quelle idee erano state altre. Se egli scrive, lo fa in quanto viaggiatore indignato da una realtà di cui è testimone - la riduzione dell'uomo a strumento di lavoro - che viene criticata 
apertamente in sostegno dell'abolizione. Anche se la polemica trovò degli illustri sostenitori, tra cui Condorcet, i Voyages ebbero scarso successo. Poco prima della Rivoluzione, la pastorale Paul et Virginie (1788), che è certamente il capolavoro dell'autore, ebbe invece un'ampia ricezione. Il libro mette in scena una relazione amorosa nell'isola Maurizio, dove si ripresenta l'immagine negativa della società coloniale e della schiavitù, a margine delle vicende letterarie di un'opera che presenta con maestria un paesaggio colorato di esotismo e l'idealizzazione della natura. Lo scrittore incarnava una certa libertà di pensiero, affatto lontana dalla definizione proposta nell'Essai sur les gens de lettres da D'Alembert, suo sostenitore. Ma il vincolo intellettuale più importante fu senz'altro quello con Rousseau, di cui Bernardin de Saint-Pierre fu amico e seguace, pur coltivando il racconto filosofico alla Voltaire. Con l'eccezione di quest'ultimo romanzo, Bernardin de Saint-Pierre non diede alle sue opere letterarie una forma definitiva. Se questo stile di scrittura, da una parte, rende più complessa l'edizione delle sue opere, dall'altra essa incarna una singolare declinazione dei rapporti tra lavoro narrativo e pensiero filosofico. Se il primo consente di spostare i limiti inerenti al metodo e alla razionalità dei sistemi, il secondo trova nella prosa letteraria forme e contenuti, in un secolo in cui l'arbitraria fragilità di questa distinzione non può che fare difetto. 